Florida International University FIU Digital Commons

\title{
The relationship between cognitive ability, the big five, task and contextual performance: a meta- analysis
}

Alexander Alonso

Florida International University

DOI: $10.25148 /$ etd.FI13101600

Follow this and additional works at: https://digitalcommons.fiu.edu/etd

Part of the Psychiatry and Psychology Commons

\section{Recommended Citation}

Alonso, Alexander, "The relationship between cognitive ability, the big five, task and contextual performance: a meta-analysis" (2000). FIU Electronic Theses and Dissertations. 1077.

https://digitalcommons.fiu.edu/etd/1077 
FLORIDA INTERNATIONAL UNIVERSITY

Miami, Florida

THE RELATIONSHIP BETWEEN COGNITIVE ABILITY, THE BIG FIVE, TASK AND CONTEXTUAL PERFORMANCE: A META-ANALYSIS

A thesis submitted in partial fulfillment of the

requirements for the degree of

MASTER OF SCIENCE

in

PSYCHOLOGY

by

Alexander Alonso

2000 
To: Dean Arthur W. Herriott

College of Arts and Sciences

This thesis, written by Alexander Alonso, and entitled The Relationship between Cognitive Ability, the Big Five, Task and Contextual Performance: A Meta-Analysis, having been approved in respect to style and intellectual content, is referred to you for judgment.

We have read this thesis and recommend that it be approved.

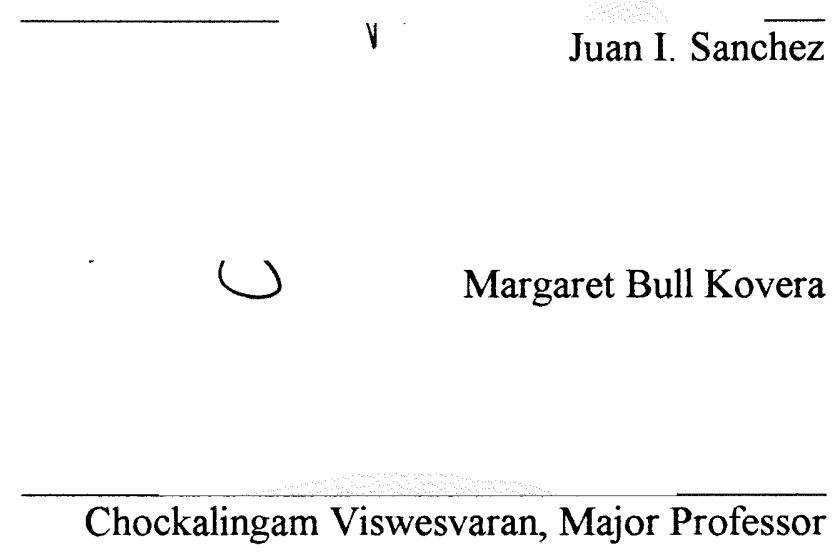

Date of Defense: September 22nd, 2000

The thesis of Alexander Alonso is approved.

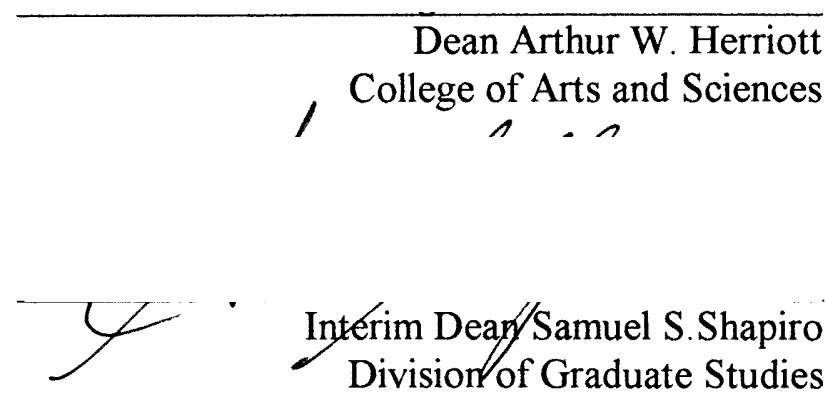

Florida International University, 2000 


\section{DEDICATION}

It is my honor to dedicate this thesis to the people who have made such a difference not only in my time in graduate school but also throughout my life. I dedicate this thesis to the women in my life-Susie (my wife), Gloria (my mother), Jessica (my daughter), Jessica (my sister), Ana (my godmother), and Aracely (my grandmother). I love you all very much. 


\section{ACKNOWLEDGMENTS}

I would like to thank the members of my thesis committee, Dr. Juan I. Sanchez and Dr. Margaret Bull Kovera, both of whom contribute to my thesis but also to my development. I would also like to thank the person most influential in the development of my thesis, Dr. Chockalingam Viswesvaran. If not for his help, his patience, and his nack for making light of even the most awful situations, I might never have been able to complete this thesis. I thank you all for your help and for your caring.

I would also like to acknowledge two faculty members who have given me guidance and aided me in becoming a part of this department. First, I would like to thank Dr. Michelle Marks for her compassion and for her willingness to put me on her research team. Without her, I might not be in graduate school today. Second, I would like to thank Dr. Scott L. Fraser for his willingness to make me laugh at any moment. I will treasure the time that I did know him. I am grateful for the opportunity to have come in contact with two such wonderful people.

Finally, I would like to acknowledge the students that have helped me develop into the person I am today without letting my head get too big. Namely, I would like to thank Jen Kantrowitz, Nila Sinha, Jackie Royer, Leslie DeChurch, Mark Sabella, and Fred Panzer. Without these students, I would never have gotten my self in gear. I thank you. 


\title{
ABSTRACT OF THE THESIS \\ THE RELATIONSHIP BETWEEN COGNITIVE ABILITY, THE BIG FIVE, TASK AND CONTEXTUAL PERFORMANCE: A META-ANALYSIS
}

by

\author{
Alexander Alonso \\ Florida International University, 2000 \\ Miami, Florida \\ Professor Chockalingam Viswesvaran, Major Professor
}

For years, researchers and human resources specialists have been searching for predictors of performance as well as for relevant performance dimensions (Barrick \& Mount, 1991; Borman \& Motowidlo, 1993; Campbell, 1990; Viswesvaran et al., 1996). In 1993, Borman and Motowidlo provided a framework by which traditional predictors such as cognitive ability and the Big Five personality factors predicted two different facets of performance: 1) task performance and 2) contextual performance. A meta-analysis was conducted to assess the validity of this model as well as that of other modified models. The relationships between predictors such as cognitive ability and personality variables and the two outcome variables were assessed. It was determined that even though the two facets of performance may be conceptually different, empirically they overlapped substantially $(\rho=.75$ ). Finally, results show that there is some evidence for cognitive ability as a predictor of both task and contextual performance and conscientiousness as a predictor of both task and contextual performance. The possible mediation of predictor-criterion relationships was also assessed. The relationship between cognitive ability and contextual performance vanished when task performance was controlled. 


\section{TABLE OF CONTENTS}

SECTION

PAGE

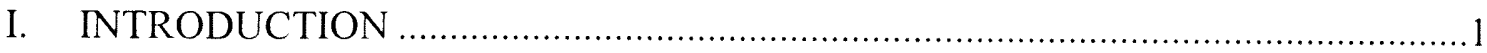

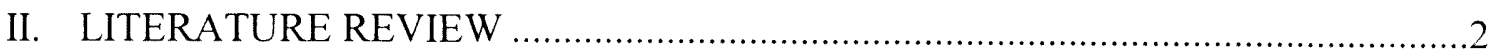

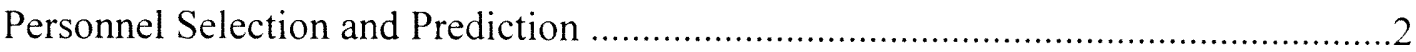

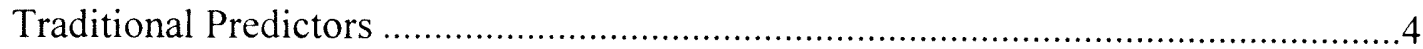

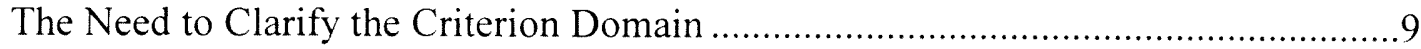

Different Models of Performance ........................................................................ 10

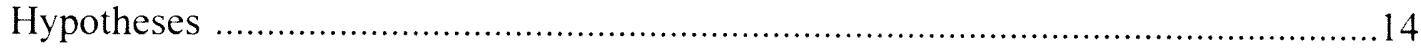

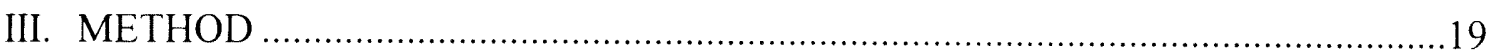

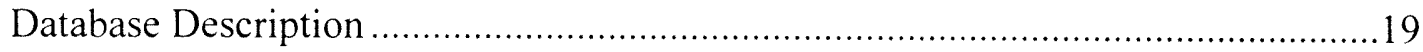

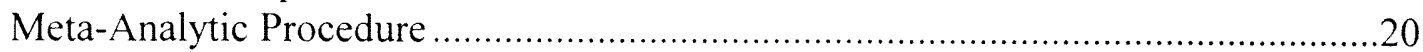

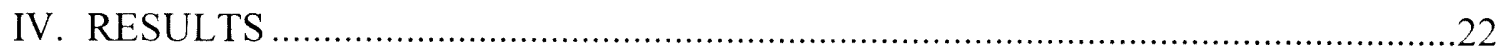

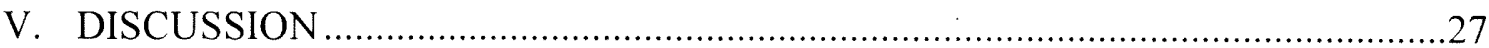

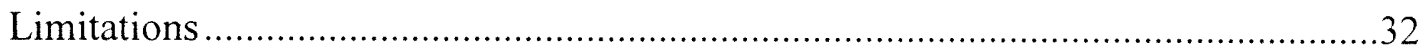

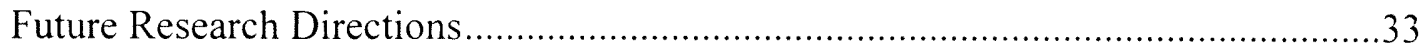

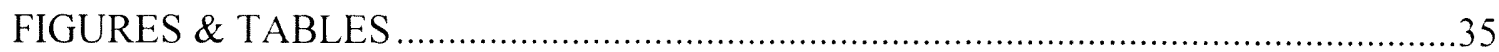

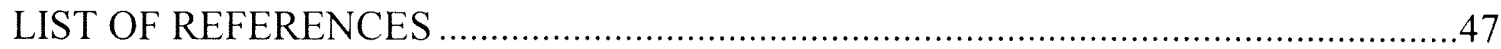

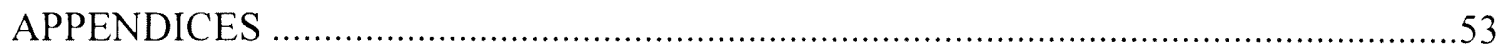




\section{LIST OF TABLES}

TABLE

PAGE

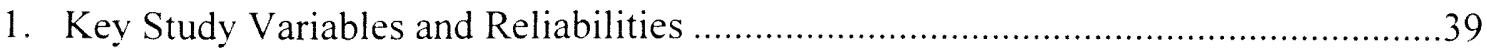

2. Relationships between Contextual and Task Performance ........................................40

3. Relationships between Six Predictors and Task Performance ...................................41

4. Relationships between Contextual Performance and Six Predictors .........................42

5. Variance Reduction Ratios for Model 3 using Rho's ..................................................43

6. Variance Reduction Ratios for Model 3 using Rbar's .................................................44

7. Variance Reduction Ratios for Model 4 using Rho's ...................................................45

8. Variance Reduction Ratios for Model 4 using Rbar's ..................................................46

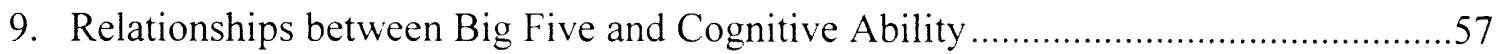

10. Intercorrelations between Big Five Personality Factors as reported in the CPI manual (Gough \& Bradley, 1996)

11. An 8X8 Correlation Matrix Using All Eight Variables and Only Observed Average Correlations .58

12. An $8 \times 8$ Correlation Matrix Using All Eight Variables and Only True Score

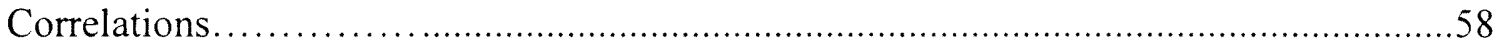

13. Goodness of Fit Indices for Model 1-4 using Rho's and Rbar's. .60 


\section{The Relationship between Cognitive Ability, the Big Five, Task and Contextual Performance: A Meta-Analysis}

\section{INTRODUCTION}

Personnel selection is a central function in industrial/organizational psychology (Guion, 1998). Organizations need people to accomplish or meet their goals for productivity, for community involvement, and for many other reasons. To do this, both researchers (Borman \& Motowidlo, 1993; Campbell et al., 1990; Motowidlo \& Van Scotter, 1994;Viswesvaran et al., 1996) and human resources decision-makers have used variables such as cognitive ability or integrity or other personality variables to predict which individual would have higher productivity and performance in other outcome variables. The problem, however, is the lack of understanding about the relationships between traditional predictors of performance and different job performance outcomes.

The primary purpose of the research paper is to test meta-analytically the relationships between traditional predictors of performance such as cognitive ability as well as the Big Five personality factors (i.e., conscientiousness, agreeableness, emotional stability, openness to experience, and extraversion) and job performance dimensions such as task and contextual performance. A second purpose is to test the validity of existing models of task and contextual performance (Borman \& Motowidlo, 1993) as well as alternate models. The study is significant for three reasons. First, it helps to clarify what predictors should be used to predict performance on the job. Second, it investigates whether one particular kind of on-the-job performance influences other kinds of on-the- 
job performance. That is, inter-relationships among performance dimensions and how they interact with predictors is explored. Third, the study is significant because of its implications for human resources and personnel managers across all kinds of organizations. Knowledge of how predictors affect different dimensions of performance is critical for effective intervention in the organization.

\section{$\underline{\text { Personnel Selection and Prediction }}$}

In personnel decisions, industrial psychologists are asked to choose individuals for the purposes of filling the needs of an organization. Unfortunately, decision makers cannot know with absolute certainty the outcomes of any assignment; thus, one must make "predictions" about these outcomes based on the available information on all the applicants. In order to make these "predictions", one must be successful in: 1) measurement and 2) prediction (Wiggins, 1973; Cascio, 1998; Guion, 1998). Measurement entails the collection of information on each applicant's cognitive ability levels, personality traits, and other variables that are relevant to the performance of the job to be filled. Prediction involves the combination of the collected data in such a manner as to allow one to decrease predictive error in forecasting the performance of that individual in the job to be filled (Guion, 1998; Wiggins, 1973). Together, these two procedures allow industrial/organizational psychologists to examine the information on all applicants in order to predict the one most capable of performing well or best on the job to be filled. Basically, these two steps are the essential ingredients of any personnel selection program. Prediction and measurement are crucial towards reaching a goal in terms of the utility of applicants (Cascio, 1998). 
Traditionally, selection is based on a measurement of knowledge, skills, abilities, and other intangibles (Cascio, 1998). These knowledge, skills, abilities, and other intangibles (otherwise known as KSAO's) can range from one's ability to solve complex scientific problems such as looking for the volume of the Mississippi River to an individual's skill at woodcarving and carpentry (Bernardin \& Russell, 1997). Guion (1998, p. 113) summed up the first step of the selection process with the following question: "What variables are the most likely to predict the criterion?" Once this question has been answered, the question then becomes "How does one measure these variables or predictors?" Here, the concern becomes which tools should be employed to measure the predictors (Cascio, 1995, 1998, p. 215; Nunnally \& Bernstein, 1994). Tools such as tests, structured interviews, assessment centers, and a host of other selection techniques then enable organizations and decision makers to measure the predictors from each available applicant (Guion, 1977, 1998).

Once the measurement and collection of data has been completed, the process of interpretation and comparison becomes the vital step. That is, the integration and interpretation of the collected data becomes important because it will enable the decision maker to incorporate all the information necessary and to make the most appropriate "prediction" (Cascio, 1998). Of course, the proper "prediction" is the selection of an individual who will be the most productive and valuable to the organization. Yet, there is no guarantee that this "prediction" will be successful, but with selection the likelihood that the chosen individual will perform exceptionally is increased (Cascio, 1995, 1998; Guion, 1998). 


\section{$\underline{\text { Traditional Predictors }}$}

There exists a limitless pool of predictors for job performance (Guion, 1998). Choosing the proper predictors for the criterion known as job performance is vital for selecting the proper personnel. Often choosing predictors becomes an issue of which is most reliable and valid as well as cost effective (Sackett et al., 1998). Traditionally, two classes of predictors fit these criteria. These are cognitive ability and personality. Together, these predictors can predict a variety of job performance criteria (Borman $\&$ Motowidlo, 1993). Cognitive ability and personality are important predictors available to the decision maker and organization.

\section{Cognitive Ability}

Common work-related cognitive activities and tasks include reading verbal or graphic materials, understanding the principles that make things work, planning events or procedures, solving problems, or perceiving signs of trouble in equipment or in human interactions or contradictions in plans (Guion, 1998). These tasks, and many more, rely on an individual's cognitive ability or intellect or general mental ability (Guilford, 1956; Guion, 1998; Sternberg \& Detterman, 1986). Guion (1998, p. 214) defined cognitive ability as "abilities to perceive, process, evaluate, compare, create, understand, manipulate, or generally think about information and ideas."

In personnel selection, cognitive ability plays a large part in almost all organizational decisions. Testing applicants for their cognitive abilities (specific or global) is something which has become commonplace in the workplace (Sackett et al., 1998). Testing for cognitive ability is useful for organizations seeking qualified 
applicants. Testing for cognitive ability is timesaving and economical because cognitive ability tests for the most part are reliable, valid, and allow for mass administration (Cascio, 1998). In essence, tests such as the Scholastic Aptitude Test, the General Aptitude Test-Battery, the Armed Services Vocational Aptitude Battery, and the General Record Examination can all lay claim to being reliable and valid measures of cognitive ability because of extensive norming and mass administration (Groth-Marnat, 1999; Nunnally \& Bernstein, 1994). These examinations provide organizations with some measure of a person's cognitive ability. These tests of cognitive ability give decision makers the chance to learn about an individual's skills and abilities in verbal and quantitative realms as well as in more specifics domains such as spatial ability, reading comprehension, and mechanical expertise (Groth-Marnat, 1999). These tests can give organizations an idea of how well a prospective employee will be capable of receiving tasks and carrying them out. Tests of cognitive ability are valuable to organizations because of their utility, particularly, in the selection process.

Measuring cognitive ability provides employers with, potentially, the best prediction of whether or not an applicant can perform on-the-job duties (Schmidt \& Hunter, 1998). This ability to predict performance using cognitive ability measures is important to organizations. In fact, as a lone predictor of job performance cognitive ability has been shown to be valid at the .50s (Murphy, 1996; Sackett et al., 1998). Moreover, major tests of cognitive ability such as the ASVAB, Wonderlic, WAIS-III, and GATB range in internal consistency from .65 to .77 with test-retest reliabilities from .59 to .86 (Groth-Marnat, 1999; Guion, 1998; Murphy, 1996). Cognitive ability tests are 
without question useful to learning about the knowledge, skills, and abilities of potential applicants.

Cognitive ability has an extensive history as a predictor of job performance as well as performance in other settings (Pearlman, 1980; Ree et al., 1994; Smither et al., 1993). Researchers such as Pearlman (1993) and Ree et al. (1994) have examined the role of cognitive ability in predicting job performance in a variety of settings. For example, Ree et al. (1994) found that $g$ predicts job performance in a military setting whereas Smither et al. (1993) reports validity evidence in civilian workplace settings. Furthermore, Pearlman (1980, p. 4) found support for general mental ability as the best predictor of job performance" in particular jobs such as clerical positions where it predicted about $49 \%$ of the variance in proficiency in clerical work. Whether measured globally or specifically, cognitive ability is useful for predicting performance of on-thejob tasks and duties (Guion, 1977; Muchinsky, 1997).

\section{Personality}

Several predictors other than cognitive ability predict job performance (Borman \& Motowidlo, 1993; Guion, 1998; Organ, 1988; Van Scotter \& Motowidlo, 1996). In many cases, it is a combination of predictors that yields the most reliable and valid decision about job performance (Austin \& Villanova, 1992). After cognitive ability, the next most studied predictor in the area of personnel selection is personality (Barrick \& Mount, 1991; Borman \& Motowidlo, 1993; Organ, 1988; Rothstein et al., 1994; Van Scotter \& Motowidlo, 1996).

Industrial psychologists in particular, and psychologists in general, have studied 
personality as a predictor of behaviors such as job performance, deviant behavior in the workplace, and work group cohesion (Borman \& Motowidlo, 1993; Van Scotter \& Motowidlo, 1994). Much of the early research on personality, however, was centered on simply defining personality and constructing a grand theory (Guion, 1977, 1998).

Research in personality reached a point where it was so troubling and of questionable use that it began to slow up. In particular, critics claimed that a variety of personality inventories lacked criterion and construct validity (Hough, 1992). This could have been because of the lack of agreement on the definition of personality and the most useful way to measure it. Others still claimed that this dearth of personality research was directly linked to the development and passing of the Civil Rights Act of 1964. This is because the Civil Rights Act of 1964 made provisions for the use of "professionally developed ability tests related to job performance" but did nothing of the sort for personality tests (Gross, 1962, p. 34). Finally, others such as Mischel (1968) insisted that the behavior of individuals was determined by the situational factors surrounding the individuals than by a system of traits that were innate to the individuals. Many agreed with all of the criticisms, leaving personality research almost dead in applied psychology.

However, recent years have seen a resurgence. In 1991, Barrick and Mount put together a meta-analytic review summarizing the advantages of personality in predicting job performance. Others still sought to develop a theory that could be employed by those attempting to conduct research involving personality. The Big Five personality model or the Five-Factor model was proposed as an answer (Costa \& McCrae, 1992; Goldberg, 1981). This model was developed using factor analysis applied to descriptors of behavior 
and yielded five factors: 1) extroversion 2) agreeableness 3 ) conscientiousness 4) emotional stability and 5) openness to experience (Guion, 1998; Muchinsky, 1997). These five dimensions were hypothesized to comprehensively describe the personality of an individual. Despite the fact that many disagreed on the naming of the five dimensions, few argued about the definitions (Digman, 1990). Finally, as Goldberg (1995) put it, applied psychologists were employing the Big Five model so much that its dominance resembled an "emerging consensus." Psychologists now had some common theory to define personality.

Today, personality proves to be a useful predictor of job performance. In particular, many point to its incremental validity of prediction if used with other predictors such as cognitive ability (Borman \& Motowidlo, 1993; Borman, Hanson, \& Hedges, 1997; Van Scotter \& Motowidlo, 1996). Personality testing for the purposes of employee selection is vital to a variety of organizations. Police organizations are some of the many organizations, which employ personality tests such as the Minnesota Multiphasic Personality Inventory to select qualified applicants from large applicant pools. Not only are personality measures used to make decisions for selection, but other organizations such as Bellsouth Communications, American Telephone and Telegraph, and Home Depot use these tests to make employment decisions such as promotions and positioning (Bernardin \& Russell, 1997; Cascio, 1998). Furthermore, validation studies of personality measures such as the California Personality Inventory and Hogan Personality Inventory have been performed in a variety of field settings (Groth-Marnat, 1999; Hogan, Hogan, \& Roberts, 1996). 


\section{The Need to Clarify the Criterion Domain}

But what is the criterion that is predicted by various predictors such as cognitive ability and personality? The issue of criteria is one that could remain debatable for a long time to come. For a variety of reasons, criterion research has been and should continue to be an open area of questioning. Austin and Villanova (1992) reviewed the area of criterion research from 1917 to 1992 and noted a variety of reasons why research on criteria needed to be improved as well as expanded. Furthermore, they found that most research in industrial/organizational psychology was devoted to determining and improving ways to measure or to validate predictors and not criteria. There also exists a dearth of refined theories of performance to apply to specific situations in both the field and laboratory settings. For these reasons, it is important to expand and explicate the criterion domain.

The lack of theoretical frameworks inhibits the proper understanding and study of criteria such as job performance (Austin \& Villanova, 1992; Borman \& Motowidlo, 1993). There is a lack of theories that try to explain the relationship between dimensions of performance and a variety of predictors such as spatial ability, conscientiousness, etc. In order to explicate the criterion domain one must have some idea of how the criteria is related to the predictor. This has been investigated by a variety of researchers (Borman \& Motowidlo, 1993; Guion, 1965; Organ, 1988; Van Scotter \& Motowidlo, 1996). This particular reason for explicating the criterion domain is crucial. That is, without a proper understanding of criteria and how they relate to other constructs, it becomes doubly difficult to understand the way that predictors are related to criteria as well as how to 
measure them. Thus, it becomes important for one to understand not only the criteria but to have a general framework by which the criteria relate to predictors.

\section{Different Models of Performance}

In terms of personnel selection, the importance of models of performance is quite apparent. Models of performance are often used to establish a link between criteria and predictors (Guion, 1998). Once a model of performance is chosen, selecting proper predictors becomes much easier. Models of job performance are key for this reason. A variety of researchers have assembled or developed theories of performance that are worthy of notice. Researchers such as Campbell et al. (1993) argued that performance is cognitive, motor, psychomotor, or interpersonal behavior of an individual that is relevant to the goals of the organization and is measurable (Guion, 1998). Furthermore, Campbell et al. (1993) went on to postulate three determinants of performance: 1) declarative knowledge, 2) procedural knowledge, and 3) motivation. Performance was broken down into eight general factors. The eight factors are: 1) job specific task proficiency, 2) non-job specific task proficiency, 3) written and oral communication task proficiency, 4) demonstrating effort, 5) maintaining personal discipline, 6) facilitating peer and team performance, 7) supervision/leadership, and 8) management/administration.

Campbell's model is but one of the many alternate models that have been postulated. Viswesvaran, Ones, and Schmidt (1996) reviewed all criterion measures used in the literature and identified a ten-component model. The ten components identified by Viswesvaran et al. (1996) were: 1) overall job performance, 2) job performance or 
productivity, 3) quality, 4) leadership, 5) communication competence, 6) administrative competence, 7) effort, 8) interpersonal competence, 9) job knowledge, and 10) compliance with or acceptance of authority.

Conway (1999) proffered yet another model of job performance. Although this model is focused on managerial jobs, the findings are noteworthy. Conway identifies four dimensions as comprising overall job performance. These four dimensions are: 1) job dedication which is comprised of doing whatever it takes to get a job done, exerting effort, and confronting problems, 2) interpersonal facilitation or the effectiveness in interpersonal relations, 3) technical-administrative task performance which entails productivity, quality of work, and quantity of output as well as resourcefulness and ability to forecast and budget effectively, and 4) leadership task performance or dynamism, leading employees, and setting a developmental or organizational climate.

Finally, another theory of job performance was introduced by Borman and Motowidlo (1993). Their theory of task performance versus contextual performance attempted to differentiate from task performance on-the-job behaviors that were not dependent on the completion of core tasks (Borman \& Motowidlo, 1993; Conway, 1999; Van Scotter \& Motowidlo, 1996). These behaviors were called "contextual performance". Contextual performance included staying late at work on short notice, aiding fellow co-workers in the completion of tasks, arriving on-time with regularity, helping solve conflicts in the work group, and helping newcomers ease into a new job. These behaviors and many more are what comprise contextual performance. Borman and Motowidlo (1993) argued that these behaviors were quite different from task behaviors 
for the following reasons. First, contextual behaviors are desirable but not necessary whereas task behaviors are. Second, contextual behaviors are similar in all or most jobs while task behaviors vary from job to job. Third, and, most importantly, contextual behaviors are related to personality dimensions while task behaviors are clearly more related to skills and abilities. Here, Borman and Motowidlo provided a framework for understanding the relationship between predictors (cognitive ability and personality) and criteria (task and contextual performance). In essence, they made the case for the prediction of task performance from cognitive ability and the prediction of contextual performance from personality variables such as conscientiousness and agreeableness.

In a set of studies conducted by Borman and Motowidlo (1993) and Motowidlo and Van Scotter (1996), this model of task and contextual performance was put to the test. Furthermore, Conway (1999) conducted a meta-analytic review of the model using studies that he felt met his definitions of contextual performance and task performance. In these studies, efforts to correlate personality variables with contextual performance as well as ability with task performance were made. However, only moderate correlations were found for these relationships. Conway as well as Van Scotter and Motowidlo made the argument that only when the predictors are refined will there be a better understanding of the relationships between these predictors and the multidimensional criteria of job performance.

Although it is important to refine the predictors, it is equally important to refine the criteria. Essentially, one important criticism of Conway's meta-analytic review is that he included studies that were claimed to examine contextual performance. 
Unfortunately, this means that a variety constructs that might be considered similar to contextual performance by the original investigators were included in the meta-analytic review without an independent re-evaluation. Motowidlo and Van Scotter (1994, p. 475) made a distinction between task and contextual performance. They defined task performance as behaviors that "bear a direct relation to the organization's technical core, either by executing its technical processes or by maintaining and servicing its technical requirements." In contrast, they defined contextual performance as behaviors that "do not support the technical core itself as much as they support the broader organizational, social, and psychological environment which the technical core must function." I will draw my operational definitions for these criteria from these researchers (See Appendix A).

A question may arise as to whether I would need to include such behaviors as Organizational Citizenship Behaviors (OCB) (Organ, 1988) and prosocial behaviors (Brief \& Motowidlo, 1986) as part of my inclusion criteria. My response would be the same as that provided by Borman and Motowidlo (1997). These researchers provided reasons why constructs such as OCBs and prosocial behaviors are not entirely equivalent to contextual performance. They discussed issues such as organizational commitment and criterion deficiency. In essence, they pointed out that constructs such as OCB differ from contextual performance because they include assumptions about organizational commitment. Also, they noted that constructs such as OCB and prosocial behaviors are merely specific facets of contextual performance but do not comprise the global construct of contextual performance. Finally, they pointed out that OCBs are limiting because they 
only consider jobs where there is an organization involved. This distinction is important because when one considers contextual performance it becomes clear that it does not apply only to jobs in large organizations but to all types of jobs. It is for these reasons that I have chosen to use studies where both task and contextual performance are operationalized in the global sense. In this thesis, I meta-analytically test the ability-task performance, personality-contextual performance relationship by cumulating data from studies that explicitly stated assessing task and contextual performance (See Figure 1). There are two hypotheses that go along with the model advanced by Borman and Motowidlo (1993):

H1a: Cognitive ability should correlate with task performance more than would the Big Five personality factors.

H1b: The Big Five personality factors should correlate with contextual performance more than would cognitive ability.

\section{Alternate Models of Performance to be Analyzed}

In addition to refining predictors and criteria, it is necessary to consider the possibility that the low correlations found by Conway (1999) and Motowidlo and Van Scotter (1996) indicate support for alternate models. The second purpose of the proposed meta-analysis is to test a variety of models involving predictors such as cognitive ability and personality (i.e., the Big 5 factor structure) and the criteria of contextual and task performance. Essentially, I develop a set of possible models of how these variables may relate to one another and test them using data from the meta-analytic cumulation.

There are three additional models which are tested: 1) one model examining the 
relationships between all eight of the following variables: cognitive ability, conscientiousness, extraversion, agreeableness, emotional stability, openness to experience, task performance and contextual performance (See Figure 2) and 2) a partialmediation model where contextual performance mediates the relationship between the Big Five variables (i.e., conscientiousness, extraversion, agreeableness, emotional stability, and openness to experience) and task performance as well as the relationship between cognitive ability and task performance, and 3) a partial-mediation model where task performance mediates the relationship between the Big Five personality variables and contextual performance as well as the relationship between cognitive ability and contextual performance (See Figures $3 \& 4$ ). Examining the viability of each of these models will hopefully yield results that enrich our understanding of the processes by which predictors and criteria are linked.

The first alternate model discussed is essential to the entire meta-analytic review because it gives the researcher the correlations between all eight variables. Moreover, it is truly a test of the relationships between all the variables involved in Borman \& Motowidlo's theory (1993). Basically, this all-to-all model relates the following eight variables: 1) cognitive ability, 2) task performance, 3) contextual performance, 4) conscientiousness, 5) agreeableness, 6) extraversion, 7) openness to experience, and 8) emotional stability. In essence, this model is used to assess which predictors (i.e., cognitive ability and the Big Five factors) do predict contextual and task performance most efficiently. In other words, it is anticipated that task performance and contextual performance will be predicted by cognitive ability and personality (Big Five). In fact. 
researchers such as Barrick and Mount (1991) claimed that predictors such as conscientiousness and agreeableness would predict job performance better than any other personality variables. Also, emotional stability has been shown by these researchers to be related to outcome variables such as satisfaction and performance. It is for these reasons that one would expect cognitive ability to predict both task and contextual performance and personality variables such as conscientiousness, agreeableness, emotional stability, and extraversion to predict both contextual and task performance. The following are the hypotheses accompanying this model:

H2a: Cognitive ability will predict task performance.

H2b: Cognitive ability will predict contextual performance.

H2c: Personality variables will predict task performance (especially conscientiousness, emotional stability, and agreeableness).

H2d: Personality variables will predict contextual performance (especially conscientiousness, agreeableness, and emotional stability).

The next model to be tested is one of partial mediation. Here, it is hypothesized that contextual performance will serve as a mediator in the link between the predictors and task performance. The reasoning behind this model is that as an individual is driven to perform prescribed tasks by both personality and cognitive ability but their performance of contextual activities will mediate their task performance. In other words, the performance of contextual activities will affect the amount of time spent on and the performance in assigned tasks. Contextual performance by definition facilitates the 
interpersonal, social, and organizational context that improves task performance. Thus, the predictors (cognitive ability, personality variables) improve task performance by their effects on contextual performance. Also, researchers such as Borman and Motowidlo (1997), Motowidlo and Van Scotter (1994), and Conway (1999) have sought better theoretical understanding as to the relationship between task and contextual performance. Essentially, questions include thoughts of orthogonality, mediation, and moderation. This model allows the researcher to examine if there is any duality to the theory of task and contextual performance. In essence, it allows one to test whether or not a high rating in contextual performance necessitates an increase of some sort in task performance. Thus, we have the following hypotheses:

H3a: The relationship between conscientiousness, emotional stability, openness to experience, agreeableness, extraversion, and task performance will be mediated by one's performance on contextual activities.

H3b: The relationship between cognitive ability and task performance will be mediated by one's performance on contextual activities.

Finally, researchers such Eagly (1996) and Conway (1999) have stated that new directions in research on task and contextual performance might include looking at how one's task performance affects their ability to perform behaviors that would be considered contextual in nature. In particular, Eagly (1996) looked at differences in perceptions of performance as attributed to sex and other cultural variables. In essence, this model is merely a reversal of model three (See Figure 4). The practical reasoning behind this theory is that a person who accomplishes what is required of them better and faster than 
others will be asked to help others or teach others how to perform better. These helping and teaching roles would be contextual performance. Unlike the previous model, this one differs in that since contextual performance is the outcome variable and task performance is the mediator, it is expected that some of the personality variables (namely extraversion) will not be related as highly as others because of its small correlations to task performance (Conway, 1999). The following hypotheses accompany this model:

H4a: The relationship between conscientiousness, emotional stability, openness to experience, agreeableness, extraversion, and contextual performance will be mediated by one's performance on task activities.

H4b: The relationship between cognitive ability and contextual performance will be mediated by one's performance on task activities. 


\section{METHOD}

\section{Database Description}

In order for a study to be included in this meta-analysis not only did the researchers need to define task and contextual performance according to Motowidlo and Van Scotter's (1994) definition, but the following criteria also had to be met: 1) the researchers must state the observed relationships between the predictor variables and the criterion variables, and 2) the researchers must be looking at the global constructs known as task performance or contextual performance. Studies that focused on only facets of contextual performance (e.g., Goodman, 1999) were not included.

The search for studies began with a variety of literature searches to locate all correlations between cognitive ability, personality (i.e., Big Five factors), task performance, and contextual performance. I obtained all published studies listed in Conway's meta-analysis (1999). Furthermore, studies were also found in published library databases such as WebLuis and PsychInfo. Next, I conducted a search for conference papers under the same topic. This was accomplished by researching each and every program for the Annual Conference of Society of Industrial and Organizational Psychologists from 1990 to 1999. This yielded an ample number of conference papers that were of possible use for the meta-analysis. With these possible leads I sent mail or electronic mail to each author of study requesting a copy of the study if unpublished or a citation if published. I sent 83 pieces of mail. Of these, only 36 authors responded, and of the 36 total responses only three studies proved useful to the meta-analysis. Taking into account the three conference papers as well as the published works found through 
library research, the final tally of studies gave me a sample of 14 studies.

A total of 507 correlations comprised the database. The total sample size (number of participants) across the 507 correlations was 213,460 . Of the total 507 correlations reported, 148 came from conference papers while the remainder came from published journal articles. The total sample included a variety of employees ranging from insurance agents to salesman to military mechanics to managers. Of these participants, a large portion (63\%) took cognitive ability from the Armed Forces Qualifying Test or the Armed Services Vocational Abilities Battery as well as personality measures such as Costa and McCrae's NEO-PI-R. As for the performance measures, participants were rated on performance by a variety of raters such as peers, supervisors, and clients. Essentially, the studies provided some way of gauging how an individual performed, in terms of tasks and contextual activities, as well as gauging either cognitive ability or personality or both.

\section{Meta-Analytic Procedures}

The testing of the hypotheses will be conducted using the Hunter and Schmidt (1990, p.185) psychometric meta-analytic procedure. The purpose of a meta-analysis is to estimate how much of the observed variance in findings can be attributed to statistical artifacts as well as to determine the average magnitude of the relationship. If a validity coefficient is highly dependent on moderators or situational factors, artifacts should not account for most of the observed variance. Meta-analysis is also useful for estimating the mean true validity of a predictor-criterion relationship (Hunter \& Schmidt, 1990). For these reasons, I use meta-analysis in order to test the proposed models of the present 
study.

Once the meta-analytically derived correlations between the six predictors and two criteria were obtained, they were used to test the alternate models. Zero-order correlations were employed to test hypotheses $1 \mathrm{a}-2 \mathrm{~d}$. Partial correlations were used to test hypotheses $3 \mathrm{a}$ and $3 \mathrm{~b}$. Partial mediation was inferred if the correlation between the predictor and task performance was reduced when contextual performance was partialled out. The variance reduction factor was computed to test the partial mediation effect (Chen \& Spector, 1991). Partial correlations and variance reduction factors were also used to test hypotheses $4 \mathrm{a}$ and $4 \mathrm{~b}$. For hypotheses $4 \mathrm{a}$ and $4 \mathrm{~b}$, the partial correlation between the predictor and contextual performance when task performance was partialled out was assessed. 


\section{RESULTS}

As with most meta-analysis, the first step in analysis is examining the statistical artifacts to be accounted for. In this case, I began by examining the reliabilities for each variable to be assessed in the meta-analysis. First, I began with the criterion variables whose mean reliabilities were .81 for task performance and .87 for contextual performance. Also, the average standard deviations for the reliability distributions were .2102 for task performance and .0619 for contextual performance. Next, I examined the reliabilities and mean standard deviations for the six predictor variables. These mean reliabilities ranged from .75 for cognitive ability with a mean standard deviation of .1626 to .80 for extraversion with a mean standard deviation of .0754 (See Table 1).

The next step in the analysis of these relationships was to conduct the metaanalysis and estimate the true score correlations for each of the thirteen relationships examined. In so doing, it was determined that when examining the relationship between contextual and task performance, one should account for the use of inter- and intra-rater correlations. The reason behind using both inter- and intra-rater correlations is that often intra-rater ratings are marred by halo error and comparing the two (inter- and intra-rater) types of correlations facilitate an exploration of the extent to which halo could possibly inflate the correlations. Therefore, in Table 2, three relationships between contextual performance and task performance are reported. The first is the total sample including both inter- and intra-rater correlations where the estimated true score correlation $(\rho)$ equaled .46 with a sample size weighted mean observed correlation of .38 . The next relationship reported is that using inter-rater correlations where $\rho=.39$ and sample size 
weighted mean observed $r=.33$. This is the correlation when two different raters rated task and contextual performance, respectively. Finally, the last relationship reported is that of task and contextual performance using intra-rater correlations. Here, the same rater rated both task and contextual performance. Here, $\rho=.75$ and the sample size weighted mean observed $r=.63$. As expected, the intra-rater was much higher than either the total or the inter-rater relationships. This higher magnitude is probably due to the effects of halo. Halo is a global evaluation that affects ratings on all dimensions (Cascio, 1998). The results of the three meta-analyses are summarized in Table 2.

Next, I examined the correlations between the six predictor variables and the two criterion variables (See Tables $3 \& 4$ ). In Table 3, the relationships between task performance and the six predictors are reported. Although all but one of the relationships between the Big Five and task performance were positive, the correlations were miniscule at best ranging from $\rho=.08$ for agreeableness to $\rho=.14$ for conscientiousness. Only extraversion was shown to be negatively related to task performance with a $\rho=-.03$ and a sample size weighted mean observed $r=-.02$. The same was not the case with cognitive ability, however. Cognitive ability had a substantial correlation with task performance.

The next set of correlations to be reported was those between contextual performance and the six predictor variables (See Table 4). Here, the $\rho$ 's ranged from .03 for extraversion to .13 for emotional stability. Also, the sample size weighted observed correlations ranged from .02 for extraversion to .10 for agreeableness and for emotional stability. In general, cognitive ability had higher validity for predicting task performance. 
All other validities were low; in fact, the true score correlations were all less than .15 , with observed correlations (i.e., validities) being typically less than .10.

As expected, cognitive ability was related to task performance, $\rho=.32$ with a sample size weighted observed correlation being .24. Coupled with the low correlations for the Big Five with task performance, the correlation of cognitive ability with task performance suggests support for hypothesis 1a. A test of statistical significance was performed by computing confidence intervals for both the true score correlations and the sample size weighted observed correlations at the $95 \%$ and $90 \%$ levels. At both levels, the relationship between cognitive ability and task performance was significantly greater than those between the Big Five personality factors and task performance. Thus, hypothesis la was supported.

However, hypothesis $1 \mathrm{~b}$ was not supported. That is, after conducting comparisons of the mean correlations and $\rho$ 's, none of the Big Five personality factors were significantly correlated to contextual performance more so than the correlation between cognitive ability and contextual performance. Further, the Big Five personality factors correlated as much with task performance (mean true score correlation of .08) as they did with contextual performance (mean true score correlation of .10 across five factors).

By looking at tables 5 through 8 , one can see that zero-order correlations, partial correlations, and variance reduction ratios are reported using both true score correlations and mean sample size weighted observed correlations. Furthermore, the tables are broken down into the four different types of correlations reported in the meta-analyses: 1) 
inter-rater true score correlations, 2) inter-rater sample size weighted observed correlations, 3) intra-rater true score correlations, and 4) intra-rater sample size weighted observed correlations. The variance reduction ratios for model three point to the fact that both conscientiousness and emotional stability as well as cognitive ability might have relationships with task performance that are partially mediated by contextual performance. Upon examining the ratios, any ratio that yields a percentage reduction between $35 \%$ and $65 \%$ was considered to be evidence of partial mediation. These percentages were selected because they represent a thirty-percent range of variance that equivalently surrounds a ratio of $50 \%$ or the ideal ratio for partial mediation. Thus, with a ratio of $49 \%$ in the true score, intra-rater category and $47 \%$ in the intra-rater, mean sample size weighted observed category, the relationship between conscientiousness and task performance was partially mediated by contextual performance. The same was evidenced in one category for the relationship between cognitive ability and task performance as well as the relationship between emotional stability and task performance. Both of these variables showed optimal reduction $(36 \%$ and $55 \%$, respectively). These findings represent partial support hypothesis $3 \mathrm{a}$ and $3 \mathrm{~b}$. In essence, hypothesis $3 \mathrm{a}$ is not fully supported because the reduction was not exhibited in all types of correlations as well as the reduction was not seen in all the Big Five factors. The same is true of the relationship between cognitive ability and task performance, which is represented by hypothesis $3 \mathrm{~b}$. Because the mediation is only evidenced in one class of correlation, there is not complete support.

As for the hypotheses that pertain to model four ( $4 a$ and $4 b$ ), support was found 
for mediation in the inter-rater, true score category for the following relationships: 1) agreeableness with contextual performance (44\%) and 2) emotional stability with contextual performance $(62 \%)$. In the intra-rater, true score correlation category the relationships between agreeableness and contextual performance $(56 \%)$ and cognitive ability and contextual performance (36\%) exhibited moderate reduction. However, interestingly, the relationship between extraversion and contextual performance was shown to disappear if not for the mediator, task performance. In the inter-rater, mean sample size weighted observed correlations category none of the relationships were reduced. However, in the intra-rater, observed category both agreeableness-contextual performance and emotional stability-contextual performance relationships showed reduction with ratios of $36 \%$ and $64 \%$, respectively. In essence, hypothesis $4 a$ was partially supported because only two of the relationships were shown to exhibit partial mediation. However, hypothesis $4 \mathrm{~b}$ was partially supported in the intra-rater, observed class. 


\section{DISCUSSION}

The results of this meta-analysis yielded findings that were interesting in the practical and theoretical sense. First, the results of the meta-analysis present evidence for some modification in theories of performance as well as the prediction of performance. Personality variables predict contextual performance as much as they predict task performance. Second, task and contextual performance may have causal relationships, suggesting that the job performance construct is more dynamic than the static conceptualization of different dimensions. Third, this gives some estimation of the magnitude of halo in the ratings by comparing inter- and intra-rater correlations.

The results of the fifteen different meta-analyses proffer evidence for the modification in the theory of task performance and contextual performance. Moreover, they present evidence for the changing of theories of prediction. In the meta-analyses, it was found that cognitive ability was significantly correlated to task performance and not to contextual performance. This result was expected and is discussed in Borman and Motowidlo's (1993) framework for task and contextual performance. Also, researchers such as Ackerman \& Heggestead (1996) and others have shown that cognitive ability or intelligence, in general, best predicts performance. Second, it was hypothesized that the relationships between agreeableness, conscientiousness, emotional stability, extraversion, and openness to experience with contextual performance would be significantly greater than those with task performance. This was not supported. In fact, the relationships between each of the personality variables and contextual performance were quite miniscule ranging from .02 to .14 . This is in direct contrast to Borman and Motowidlo's 
(1993) and Motowidlo and Van Scotter's (1994) findings where the Big Five personality factors were significantly correlated to contextual performance but not task performance. The fact that the personality factors were not significantly correlated to either of the two performance dimensions is intriguing. However, the magnitudes of correlations reported here are consistent with those reported in prior meta-analyses. For example, Barrick and Mount (1991) reported correlations that ranged from low .10 to a maximum of .23 only. Thus, neither personality nor cognitive ability has strong validities for predicting contextual performance. Other contextual variables such as job satisfaction (Williams, Sanchez, \& Viswesvaran, 2000) or goal setting (Barrick, Mount, \& Strauss, 1993) or autonomy (Borman \& Motowidlo, 1994) should be explored.

One very interesting result of the meta-analysis needs to be mentioned. When rated by one person (which is the case in most settings), task performance and contextual performance are correlated .75 . This means that $50 \%$ of the variance in task performance can be explained by contextual performance. Taking this high correlation into account as well as the findings of Williams (1999), there is evidence that contextual performance and task performance are in fact the same construct that needs to be refined. However, with an observed correlation equal to $(r=.52)$ the implication remains that only $25 \%$ of the variance in one can be explained by the other.

On the other hand, consider the test of the viability of the relationships presented in Models three and four, where variance reduction ratios were used to test the possibility of mediation. These analyses did yield some partial evidence of mediation in some of the relationships between predictors and the criteria. This is true particularly in the cases of 
emotional stability and agreeableness. Because the ratios could not be duplicated in the four possible conditions--1) inter-rater true score correlations, 2) intra-rater true score correlations, 3) inter-rater mean sample size weighted observed correlations, and 4) intrarater mean sample size weighted observed correlations--there is inconclusive evidence as for the mediation of the relationships between predictors and criteria. However, the fact that there is some evidence for mediation suggests that task performance and contextual performance are not as highly related and, thus, not the same construct.

All these suggest the need to refine our conceptualization of task and contextual performance. One way of refining them may be to do away with both and analyze if it is just one factor of performance. Another way to refine them is to factor analyze the two factors into more factors that would be more specific as when contextual performance is divided into altruism and integrity (Goodman, 1999). Much more needs to be learned about the relationship between task performance and contextual performance; nonetheless, it is becoming apparent that both need to be refined if there is to be better understanding.

One important discussion point that needs to be mentioned, however, is the kind of reliabilities used in the studies that were meta-analyzed. The method of assessing reliability used in each study is important because of its effects on the meta-analyses and, thus, variance reduction analyses. Throughout the studies used, the most common type of reliability estimate was the coefficient alpha that is frequent in internal consistency approaches. However, some critics might argue that for the purposes of this study the ideal would be an inter-rater reliability. This is because of the nature of the evaluations 
used to assess performance in the studies that were meta-analyzed. In more than half the studies, the evaluations entailed using a multiple rater approach of assessment and yet only coefficient alphas were reported. Unfortunately, these alphas are only a good measure of reliability when comparing items within a measure to the rest of the measure. Little can be said about their effect, however, on interrater reliability. This is important to this particular study because these coefficients would help in the disentanglement of the two criterion variables. This, in turn, would help create more clear and powerful models of prediction as well as refine the theoretical models. So, there is a definite need for using interrater of reliability coefficients in the analysis of the four models proffered in this thesis.

The next question addressed in this study is how the results affect theories of performance in existence. Throughout the introduction of this thesis, theories of performance are described to give perspective to the way that performance is operationalized in research. Furthermore, it is mentioned that performance is operationalized in a variety of ways ranging from general (one facet) to specific (multiple facets). The results of this study lend to the argument that performance even if multifaceted has a common core. In other words, because of the high relationship between task and contextual performance, there is evidence that there is a general factor in job performance. This is true even for inter-rater correlations that are not affected by idiosyncratic halo, and in fact reduced by rater disagreements. It is highly unlikely that all of the shared variance could be attributed to a shared halo across raters.

The findings reported here suggest that the framework offered by Borman and 
Motowidlo (1993) needs some more modification. Moreover, the results provide evidence for the integration of their two facets--task and contextual performance. In essence, this thesis does not only provide evidence for the integration of the two but perhaps for the integration of the two in the eyes of supervisors and evaluators in the workforce. This conclusion can be achieved by looking at the fact that a wide range of jobs were examined in the studies that were meta-analyzed along with the fact that multiple raters were used often.

Further, although contextual performance is operationalized as "above and beyond" task performance, both raters and performers might see contextual performance as a necessity to succeed and perform well. This would, in turn, be in keeping with some societal views as well as certain organizational cultures and climates (namely that of the military bodies and others with long traditions). The reasoning behind contextual performance as a necessity to succeed and as such prescribed task performance is that in organizations with long-standing cultures, objectives, and climates, there may be a need to meet contextual performance expectations in order to not only get ahead but to stay level. For example, in the military one may be inculcated with thoughts of helping others perform and going above and beyond the call of duty. If one does not fall into this category of performer, one might be expelled or discharged. This being the case performing contextual activities becomes a necessity and thus a prescribed task. This is an implication which is important not only to theory but to practical settings. Not only does it affect theories of performance in that it calls for the general factor of performance but it is important to organizations because it suggest that contextual performance can be 
indoctrinated to a degree where it becomes a facet of prescribed task performance.

All of the analyses presented in this thesis, point to implications both in the theoretical and practical realms. In the theoretical realm, they lead to conclusions there is a general factor in job performance much like Spearman's (1927) intelligence. In the practical realm, it is evident that contextual performance can be made a prescribed task and as such can be predicted best by cognitive ability.

\section{$\underline{\text { Limitations }}$}

There were three major limitations in general. The first of these is the fact that there were a small number of correlations. The second is variability in correlations across studies. The last of these is the lack of inter-rater reliability estimates. All of these contribute to the general underestimation and power of the results yielded by the analyses.

A small number of correlations can hinder any meta-analysis. The effect is the lack of generalizability and confidence in the results yielded by any meta-analysis. Some of the relationships studied only had six correlations. Small-sample meta-analyses are affected by second order sampling error and outliers. Because of this limitation it becomes difficult to generalize the results of this study to other populations. The only counterargument that can be offered is that the studies used in the meta-analysis were expansive in geographic and ethnic variation as was the variety of jobs that were evaluated. Further, the sample sizes were large so as to mitigate first-order sampling error. Some studies had a sample size of almost 19,000. The total sample sizes were in six figures $(>100.000)$. Thus, although studies are needed in new settings, this meta- 
analysis serves the purpose of estimating the desired relationships in the populations tested.

A small standard deviation is a function of two things: 1) little deviation from the mean and 2) a huge sample size. In this case, because of the enormous sample sizes and small number of correlations, which leads to little deviation from the mean, there are small standard deviations throughout the key study variables. As a result, there was no need to test for moderators of the bivariate relationships.

Finally, the last limitation of this study is the fact that there was an abundance of one type of reliability estimate--coefficient alpha. Because this estimate is so abundant in all of the studies, there is a dearth of inter-rater reliabilities which would be beneficial to the explication of the criterion variables and how the relate to traditional predictors. Moreover, the inconsistency between the performance appraisal approaches and the reliability estimate related to each key study variable lend to the error incurred in the estimation of the true score correlations between all of the key study variables. Thus, there is no reason to suspect that the estimation of the significance and comparison of different path coefficients were affected.

\section{$\underline{\text { Future Directions }}$}

There are two interesting directions that can be taken from this particular study. The first is the examination of task and contextual performance as one general construct that is best predicted by cognitive ability. The second is the examination of potential moderators of the predictor-contextual performance relationship.

The first of these possible directions presents some very important implications. 
If it were to be determined that task performance and contextual performance are the general construct to be known as performance, it could lead to a possible conclusion that theories of specific facets of performance are not necessarily viable nor generalizable. This would, in turn, limit an entire area of research on performance but open new avenues of research.

The second refers to a test of possible moderators of the relationship between traditional predictors and task and contextual performance. Such moderators might include autonomy, type of job, and job satisfaction. The reasoning behind such tests entails checking to see whether job-context variables like type of job can affect the relationship between predictors and performance. For example, would the type of job such as (military vs. customer service) moderate the relationship between personality variables and contextual performance?

Further some dimensions of personality such as emotional stability could serve as a moderator. For years, researchers such as Costa and McCrae (1992) and Barrick and Mount (1991) have argued as to which of the Big Five personality factors best predicts performance as well as lends to the relationships between other outcome variables such as satisfaction and commitment. The relationship exhibited here provides some minimal evidence for personality variables as predictors of task and contextual performance. Overall, this thesis provides a summary test of the hypothesis that cognitive ability predicts task performance and personality variables predict contextual performance. Although cognitive abilities predicted task performance, techniques for the prediction of contextual performance need to be improved. 
Figure 1

Borman and Motowidlo's Model (1993)
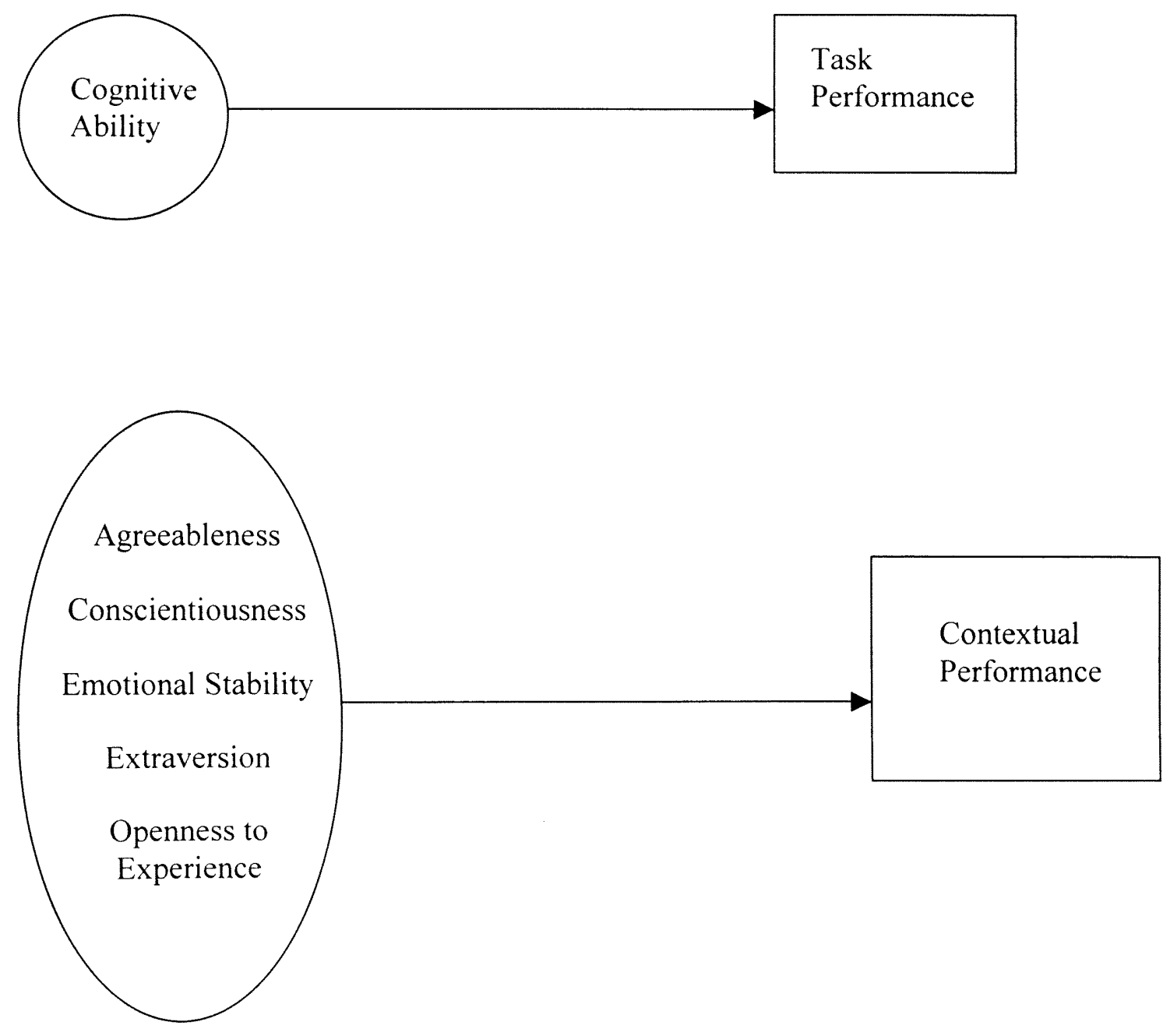
Figure 2

The All-to-All model

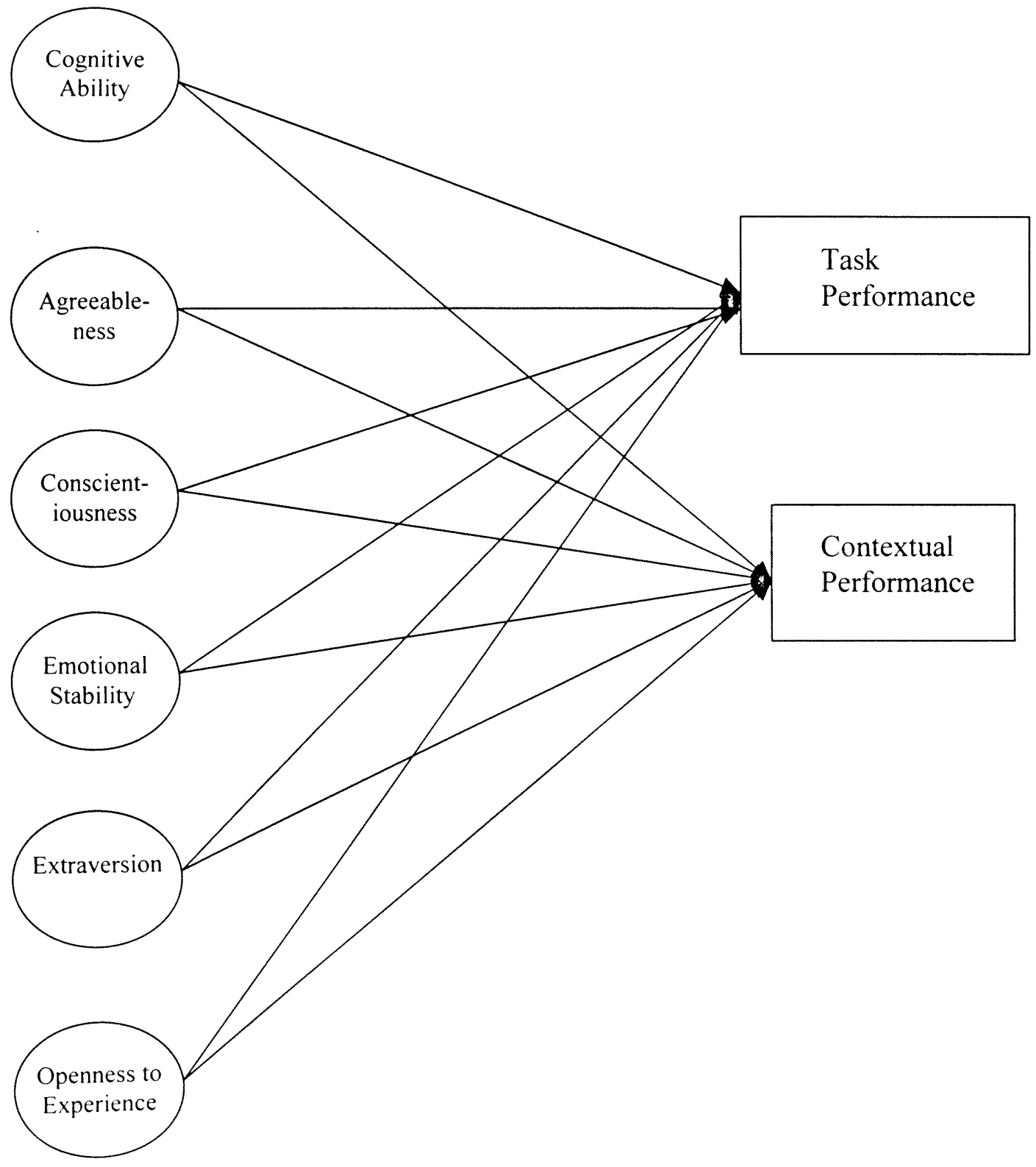


Figure 3

A model for contextual performance as a partial mediator

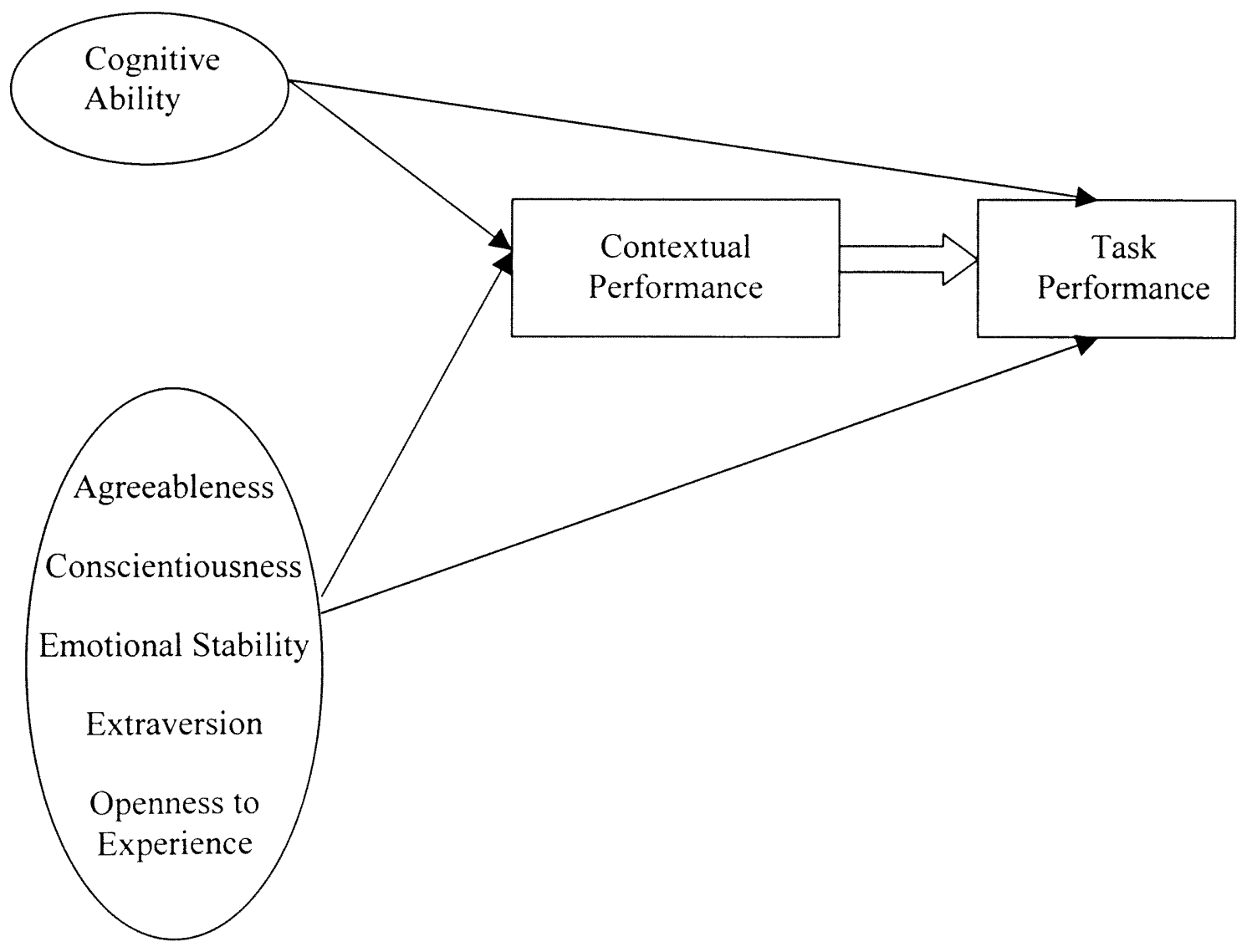


Figure 4

A model for task performance as a partial mediator

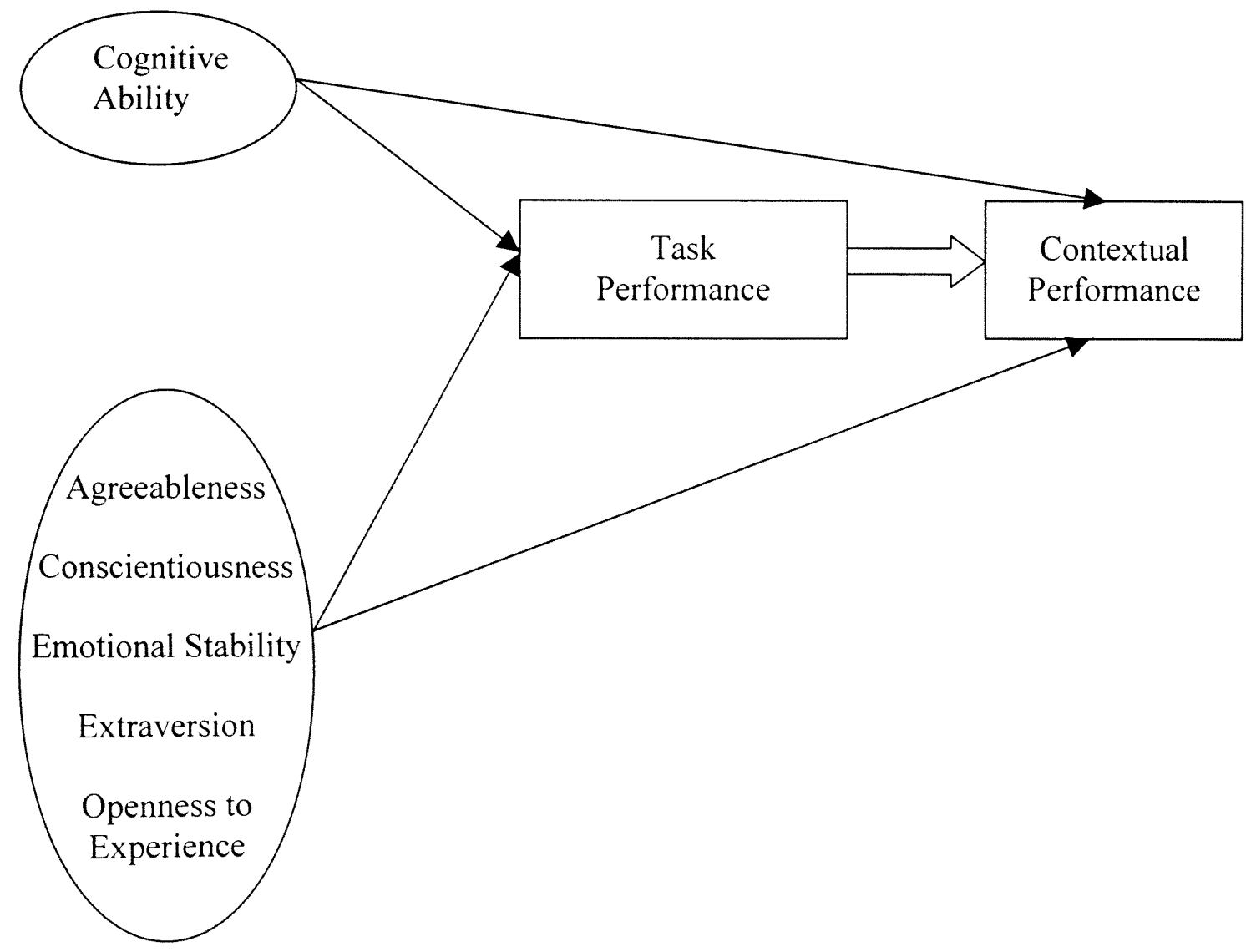


Table 1

Key study variables and reliabilities

\begin{tabular}{|c|c|c|c|c|c|c|c|c|}
\hline Variables & $\underline{\mathrm{k}}$ & $\underline{N}$ & $\frac{\text { Mean }}{\text { Reliability }}$ & $\begin{array}{l}\text { Mean } \\
\underline{\mathrm{SD}}\end{array}$ & $\underline{\operatorname{Rel}}_{\underline{f}}$ & $\underline{\mathrm{SD}}_{\mathrm{f}}$ & $\underline{\operatorname{Rel}}_{\underline{\mathrm{f} \sigma}}$ & $\underline{S D}_{\underline{f \sigma}}$ \\
\hline 1. Task Performance & 84 & 54654 & .81 & .2102 & .76 & .2474 & .58 & .0612 \\
\hline 2. Contextual Performance & 216 & 74538 & .87 & .0619 & .86 & .0528 & .74 & .0028 \\
\hline 3. Cognitive Ability & 6 & 18455 & .75 & .1626 & .81 & .1094 & .67 & .0120 \\
\hline 4. Emotional Stability & 37 & 13076 & .77 & .1015 & .76 & .1083 & .58 & .0117 \\
\hline 5. Agreeableness & 40 & 6529 & .76 & .1068 & .76 & .0698 & .58 & .0049 \\
\hline 6. Conscientiousness & 47 & 26618 & .77 & .1040 & .78 & .0621 & .61 & .0039 \\
\hline 7. Openness to Experience & 37 & 13072 & .77 & .0828 & .76 & .0599 & .58 & .0036 \\
\hline 8. Extraversion & 40 & 6518 & .80 & .0754 & .77 & .0567 & .59 & .0032 \\
\hline
\end{tabular}


Table 2

Relationships between Contextual and Task Performance

\begin{tabular}{|c|c|c|c|c|c|c|c|c|}
\hline Meta-analysis & $\underline{\mathrm{k}}$ & $\underline{N}$ & $\frac{\stackrel{\text { Mean }}{\text { Correlation }}}{\underline{\text { (rbar) }}}$ & $\underline{S D}_{\text {rbar }}$ & $\varrho$ & $\underline{\mathrm{SD}_{0}}$ & $\% \mathrm{SE}$ & $\%$ Variance \\
\hline CP-TP & 45 & 22462 & .38 & .18 & .46 & .19 & .84 & .24 \\
\hline CP-TP * & 28 & 16979 & .33 & .18 & .39 & .21 & .61 & .39 \\
\hline CP-TP ${ }^{\mathrm{a}}$ & 17 & 5483 & .63 & .10 & .75 & .13 & .34 & .19 \\
\hline
\end{tabular}

* Refers to the use of only inter-rater correlations in the meta-analysis.

a Refers to the use of only intra-rater correlations in the meta-analysis.

Note. Rbar refers to the use of mean sample size weighted observed correlations while $\varrho$ refers to the use of true score correlation estimates. 
Table 3

Relationships between six predictors and task performance

\begin{tabular}{|c|c|c|c|c|c|c|c|c|}
\hline 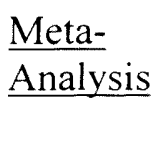 & $\underline{\mathrm{k}}$ & $\underline{N}$ & $\frac{\begin{array}{l}\text { Mean } \\
\text { Correlation }\end{array}}{\underline{\text { (rbar) }}}$ & $\underline{S D}_{(\text {rbar })}$ & $\rho$ & $\underline{S D}_{Q}$ & $\frac{\% \text { Standard }}{\text { Error }}$ & $\%$ Variance \\
\hline Agr-TP & 10 & 1640 & .05 & .0876 & .08 & .0505 & 79 & 81 \\
\hline OE-TP & 10 & 5167 & .09 & .0333 & .12 & .0000 & 171 & 198 \\
\hline Con-TP & 24 & 9922 & .11 & .0519 & .14 & .0000 & 88 & 103 \\
\hline ES-TP & 10 & 5169 & .09 & .0755 & .12 & .0782 & 34 & 38 \\
\hline EX-TP & 10 & 1636 & -.02 & .0804 & -.03 & .0232 & 95 & 95 \\
\hline g-TP & 11 & 8658 & .24 & .1486 & .32 & .1751 & 5 & 16 \\
\hline
\end{tabular}

Note. Rbar refers to the use of mean sample size weighted observed correlations while $\varrho$ refers to the use of true score correlation estimates. 
Table 4

Relationships between Contextual performance and six predictors

\begin{tabular}{|c|c|c|c|c|c|c|c|c|}
\hline$\frac{\text { Meta- }}{\text { Analysis }}$ & $\underline{\mathrm{k}}$ & $\underline{N}$ & $\frac{\begin{array}{c}\text { Mean } \\
\text { Correlation }\end{array}}{\text { (rbar) }}$ & $\underline{\mathrm{SD}}_{\text {rbar }}$ & $\varrho$ & $\underline{S D}_{R}$ & $\frac{\% \text { Standard }}{\text { Error }}$ & $\%$ Variance \\
\hline $\mathrm{CP}-\mathrm{OE}$ & 29 & 7905 & .09 & .0677 & .11 & .0374 & 79 & 79 \\
\hline CP-Agr & 30 & 4889 & .10 & .1088 & .12 & .0928 & 51 & 51 \\
\hline CP-ES & 29 & 7907 & .10 & .1184 & .13 & .1241 & 26 & 26 \\
\hline CP-EX & 30 & 4882 & .02 & .0876 & .03 & .0469 & 81 & 81 \\
\hline CP-Con & 53 & 16696 & .08 & .0699 & .10 & .0502 & 64 & 65 \\
\hline CP-g & 13 & 9797 & .04 & .0688 & .05 & .0693 & 28 & 28 \\
\hline
\end{tabular}

Note. Rbar refers to the use of mean sample size weighted observed correlations while $\varrho$ refers to the use of true score correlation estimates. 
Table 5

Variance Reduction Ratios for Model 3 using Rho's

\begin{tabular}{|c|c|c|}
\hline Zero-Order Correlation & $\frac{\text { Partialling Contextual }}{\text { Performance }}$ & Variance Reduction Ratio \\
\hline \multicolumn{3}{|l|}{ Inter-rater } \\
\hline Agr $-\mathrm{TP}=.08$ & .02 & $94 \%$ \\
\hline Cons- $\mathrm{TP}=.14$ & .12 & $27 \%$ \\
\hline $\mathrm{ES}-\mathrm{TP}=.12$ & .06 & $75 \%$ \\
\hline $\mathrm{EX}-\mathrm{TP}=-.03$ & -.05 & $-177 \%$ \\
\hline $\mathrm{OE}-\mathrm{TP}=.12$ & .07 & $66 \%$ \\
\hline $\mathrm{g}-\mathrm{TP}=.32$ & .34 & $13 \%$ \\
\hline \multicolumn{3}{|l|}{ Intra-rater } \\
\hline $\mathrm{Agr}-\mathrm{TP}=.08$ & -.03 & $86 \%$ \\
\hline Cons- $\mathrm{TP}=.14$ & .10 & $49 \%$ \\
\hline $\mathrm{ES}-\mathrm{TP}=.12$ & .03 & $94 \%$ \\
\hline $\mathrm{EX}-\mathrm{TP}=-.03$ & -.09 & $-300 \%$ \\
\hline $\mathrm{OE}-\mathrm{TP}=.12$ & .05 & $83 \%$ \\
\hline $\mathrm{g}-\mathrm{TP}=.32$ & .47 & $116 \%$ \\
\hline
\end{tabular}


Table 6

Variance Reduction Ratios for Model 3 using rbar's

\begin{tabular}{ccc}
\hline Zero-Order Correlation & $\frac{\text { Partialling Contextual }}{\text { Performance }}$ & Variance Reduction Ratio \\
& & \\
Inter-rater & & \\
& & \\
Agr- $\mathrm{TP}=.05$ & & \\
Cons- $\mathrm{TP}=.11$ & .02 & $34 \%$ \\
$\mathrm{ES}-\mathrm{TP}=.09$ & .09 & $33 \%$ \\
$\mathrm{EX}-\mathrm{TP}=-.02$ & .06 & $-125 \%$ \\
$\mathrm{OE}-\mathrm{TP}=.09$ & -.03 & $56 \%$ \\
$\mathrm{~g}-\mathrm{TP}=.24$ & .06 & $0 \%$ \\
& .24 & \\
Intra-rater & & \\
& & \\
$\mathrm{Agr}-\mathrm{TP}=.05$ & & $84 \%$ \\
$\mathrm{Cons}-\mathrm{TP}=.11$ & -.02 & \\
$\mathrm{ES}-\mathrm{TP}=.09$ & .08 & $87 \%$ \\
$\mathrm{EX}-\mathrm{TP}=-.02$ & .03 & $200 \%$ \\
$\mathrm{OE}-\mathrm{TP}=.09$ & -.04 & $80 \%$ \\
$\mathrm{~g}-\mathrm{TP}=.24$ & .04 & $36 \%$ \\
\hline
\end{tabular}


Table 7

Variance Reduction Ratios for Model 4 using rhos

\begin{tabular}{ccc}
\hline Zero-Order Correlation & Partialling Task Performance & Variance Reduction Ratio \\
\hline & & \\
Inter-rater & & \\
& & \\
Agr-CP $=.12$ & .09 & $44 \%$ \\
Ons-CP=.10 & .03 & $91 \%$ \\
$\mathrm{ES}-\mathrm{CP}=.13$ & .08 & $62 \%$ \\
$\mathrm{EX}-\mathrm{CP}=.03$ & .05 & $-177 \%$ \\
$\mathrm{OE}-\mathrm{CP}=.11$ & .06 & $70 \%$ \\
$\mathrm{~g}-\mathrm{CP}=.05$ & -.13 & $-576 \%$ \\
& & \\
Intra-rater & & \\
& & \\
$\mathrm{Agr}-\mathrm{CP}=.12$ & & \\
$\mathrm{Cons}-\mathrm{CP}=.10$ & .08 & $56 \%$ \\
$\mathrm{ES}-\mathrm{CP}=.13$ & .05 & $75 \%$ \\
$\mathrm{EX}-\mathrm{CP}=.03$ & .07 & $71 \%$ \\
$\mathrm{OE}-\mathrm{CP}=.11$ & .03 & $0 \%$ \\
$\mathrm{~g}-\mathrm{CP}=.05$ & .06 & $70 \%$ \\
& -.04 & $36 \%$ \\
& & \\
\hline
\end{tabular}


Table 8

Variance Reduction Ratios for Model 4 using rbars

\begin{tabular}{ccc}
\hline Zero-Order Correlation & Partialling Task Performance & Variance Reduction Ratio \\
\hline & & \\
Inter-rater & & \\
& & $19 \%$ \\
& & $61 \%$ \\
Agr-CP=.10 & .09 & $36 \%$ \\
Cons- $\mathrm{CP}=.08$ & .05 & $125 \%$ \\
$\mathrm{ES}-\mathrm{CP}=.10$ & .08 & $56 \%$ \\
$\mathrm{EX}-\mathrm{CP}=.02$ & .03 & $0 \%$ \\
$\mathrm{OE}-\mathrm{CP}=.09$ & .06 & \\
$\mathrm{~g}-\mathrm{CP}=.04$ & -.04 & \\
& & \\
Intra-rater & & $36 \%$ \\
& & $98 \%$ \\
$\mathrm{Agr}-\mathrm{CP}=.10$ & .08 & $64 \%$ \\
$\mathrm{Cons}-\mathrm{CP}=.08$ & .01 & $30 \%$ \\
$\mathrm{ES}-\mathrm{CP}=.10$ & .06 & $-1306 \%$ \\
$\mathrm{EX}-\mathrm{CP}=.02$ & .04 & \\
$\mathrm{OE}-\mathrm{CP}=.09$ & .04 & \\
$\mathrm{~g}-\mathrm{CP}=.04$ & -.15 & \\
& & \\
& &
\end{tabular}




\section{LIST OF REFERENCES}

Austin, J. T. \& Villanova, P. (1992). The criterion problem: 1917-1992. Journal of Applied Psychology, 77, 836-874.

*Avis, J., Kudisch, J. D., \& Fortunato, V. J. (2000). Combining cognitive ability and integrity testing: Economic and social advantage. Paper presented at the $15^{\text {th }}$ Annual Conference of the Society for Industrial and Organizational Psychology, April 2000, New Orleans, LA.

Barrick, M. R. \& Mount, M. K. (1991). The Big Five personality dimensions and job performance: A meta-analysis. Personnel Psychology, 44, 1-26.

Bernardin, J. H., \& Russell, J. E. A. (1997). Human resource management: An experiential approach. Boston: Irwin/McGraw-Hill.

Borman, W. C., Hanson, M. A., \& Hedge, J. W. (1997). Personnel selection. Annual Review of Psychology, $48,299-337$.

*Borman, W. C. \& Motowidlo, S. J. (1997). Task performance and contextual performance: The meaning for Personnel Selection Research. Human Performance, 10(2), 99-109.

---. (1993). Expanding the criterion domain to include elements of contextual performance. In N. Schmitt \& W. C. Borman (Eds.), Personnel selection in organizations. San Francisco: Jossey-Bass.

*Borman, W. C., White, L. A., \& Dorsey, D. W. (1995). Effects of ratee task performance and interpersonal factors on supervisor and peer performance ratings. Journal of Applied Psychology, 80(1), 168-177.

Campbell, R. J., \& Bray, D. W. (1993). Use of an assessment center as an aid in management selection. Personnel Psychology, 46, 691-699.

Cascio, W. F. (1998). Applied psychology in human resources management (Fifth ed.). Upper Saddle River, NJ: Prentice Hall.

----. (1995). Whither industrial and organizational psychology in a changing world of work? American Psychologist, 50(11), 928-939. 
Cattell, R. J. (1963). Theory of fluid and crystallized intelligence: A critical experiment. Journal of Educational Psychology, 5t, 1-22.

Chen, P. Y., \& Spector, P. E. (1991). Negative affectivity as the underlying cause of correlations between stressors and strains. Journal of Applied Psychology, 76(3), 398-407.

Conway, J. M. (1999). Distinguishing contextual performance from task performance for managerial jobs. Journal of Applied Psychology, 84(1), 3-13.

Costa, J. P. \& McCrae, R. R. (1992). The five-factor model: Issues and applications (Special Topics). Journal of Personality, 60(2), 175-532.

Cronbach, L. J. \& Gleser, G. C. (1965). Psychological tests and personnel decisions (2nd ed.). Urbana, IL: University of Illinois Press.

Digman, J. M. (1990). Personality structure: Emergence of the five-factor model. Annual Review of Psychology, 41, 417-440.

*Fallon, J. D., Avis, J. M., Kudisch, J. D., Gornet, T. P., \& Frost, A. (1998). Conscientiousness as a predictor of productive and counterproductive behaviors. Paper presented at the 13th Annual Conference of the Society for Industrial and Organizational Psychology, April 1998, Dallas, TX.

Gardner, H. (1983). Frames of mind: The theory of multiple intelligences. New York: Basic.

Goldberg, L. R. (1995). What the hell took so long? Donald Fiske and the bigfive factor structure. In Shrout, P. E. \& Fiske, S. T. (Eds.), Advances in personality research, methods, and theory: A festschrift honoring Donald Fiske. Hillsdale, NJ: Lawrence Erlbaum Associates.

----. (1981). Language and individual differences: The search for universals in personality lexicons. In Wheeler, L. (Ed.), Review of personality and social psychology Vol. 2, pp. 141-165. Beverly Hills: Sage.

*Goodman, S. A. (1996). Expanding the performance domain: Who says nice guys finish last? Paper presented at the 11 th Annual Conference of the Society for Industrial and Organizational Psychology, 1996, St. Louis, MO.

Gross, M. L. (1962). The brain watchers. New York: Random House. Groth-Marnat, G. (1999). Handbook of psychological assessment (3rd ed.).

New York: John Wiley \& Sons, Inc. 

Hill.

Guilford, J. P. (1956). Psychometric methods (3rd ed.). New York: McGraw-

Guion. R. M. (1998). Assessment, measurement, \& prediction for personnel decision. Mahwah, NJ: Lawrence Erlbaum Associates, Publishers. 101-388.

-.-. (1977). Recruiting, selection, and job placement. In M.D. Dunnette (Ed.), Handbook of industrial and organizational psychology (777-828). Chicago: RandMcNally.

-.-. (1965). Personnel Testing. New York: McGraw-Hill.

Guion, R. M. \& Gottier, R. F. (1965). Validity of personality measures in personnel selection. Personnel Psychology, 18, 135-164.

${ }^{*}$ Hattrup, K., O'Connell, M. S., \& Wingate, P. H. (1998). Prediction of multidimensional criteria: Distinguishing task and contextual performance. Human Performance, 11(4), 305-319.

Hogan, R., Hogan, J., \& Roberts, B. W. (1996). Personality measurement and employment decisions. American Psychologist, 51, 469-477.

Hough, L. M. (1992). The "big five" personality variables--construct confusion: Description versus prediction. Human Performance, 5, 139-155.

Humphreys, L. G. (1979). The construct of general intelligence. Intelligence, 3, 105-120.

Hunter, J. E. \& Hunter, R. F. (1984). Validity and utility of alternative predictors of job performance. Psychological Bulletin, 96, 72-98.

Hunter, J. E. \& Schmidt, F. L. (1990). Methods of meta-analysis: Correcting error and bias in research findings. Newbury Park, CA: Sage.

Lewin, K. (1936). Principles of topological psychology. New York: McGrawHill.

Linn, R. L. (1986). Comments on the g factor in employment testing. Journal of Vocational Behavior, 29, 438-444.

*Lyne, R., Sinclair, R. R.. \& Gerhold, C. (1998). Personality and job performance: Matching predictor and criterion domains. Unpublished manuscript, University of Tulsa. 
*McManus, M. A., \& Kelly, M. L. (1999). Personality measures and biodata: Evidence regarding their incremental predictive value in the life insurance industry. Personnel Psychology, 52, 137-148.

Mischel, W. (1968). Personality and assessment. New York: Wiley.

*Motowidlo, S. J. \& Van Scotter, J. R. (1994). Evidence that task performance should be distinguished from contextual performance. Journal of Applied Psychology, $79,475-480$.

Muchinsky, P. M. (1997). Psychology applied in work (5th ed.). Pacific Grove, CA: Brooks/Cole Publishing.

Murphy, K. R. (1996). Individual differences and behavior in organizations: Much more than g. In Murphy, K. (Ed.), Individual differences and behavior in organizations (pp. 3-30). San Francisco: Jossey-Bass.

Nunnally, J. C. \& Bernstein, I. H. (1994). Psychometric Theory (3rd ed.). New York: McGraw-Hill.

Ones, D., Viswesvaran, C., \& Schmidt, F. L. (1993). Comprehensive metaanalysis of integrity test validities: Findings and implications for personnel selection and theories of job performance. Journal of Applied Psychology, 78, 679-703.

Organ, D. (1988). Organizational citizenship behavior: The good soldier syndrome. Lexington, MA: Lexington.

Pearlman, K. (1980). Job families: A review and discussion of their implications for personnel selection. Psychological Bulletin, 87(1), 1-28.

Ree, M. J., Earles, J. A., \& Teachout, M. S. (1994). Predicting job performance: Not much more than $g$. Journal of Applied Psychology, 79(4), 518-524.

*Robie, C., \& Ryan, A. M. (1999). Performance monitoring as a moderator of the relations between two conscientiousness measures and task performance. Journal of Business and Psychology, 13(3), 391-406.

Rothstein, M., Jackson, D. N., \& Tett, R. P. (1994). Personality and job performance: Limitations and challenges to validation research. In R. C. Page (Chair), Personality and job performance: Big five versus specific traits. Symposium conducted at the Ninth Annual Conference of the Society for Industrial and Organizational Psychology, April, 1994, Nashville, TN. 
Sackett, P. R., Gruys, M. L., \& Ellingson, J. E. (1998). Ability-personality interactions when predicting job performance. Journal of Applied Psychology, 83(4), 545-556.

Schmidt, F. L., \& Hunter, J. E. (1998). The validity and utility of selection methods in personnel psychology: Practical and theoretical implications of 85 years of research findings. Psychological Bulletin, 124(2), 262-274.

Schneider, R. J. \& Hough, L. M. (1995). Personality and industrial/organizational psychology. In Cooper, C. L. \& Robertson, I. T. (Eds.), International review of industrial and organizational psychology (pp. 75-130). Chichester, England: Wiley.

*Scullen, S. E. (1998). Toward greater understanding of the construct validity on managerial performance ratings. Unpublished doctoral dissertation, University of Iowa.

* Sinclair, R. R., \& Adrian, D. (1999). Preliminary validity evidence for a multifaceted hierarchical job performance model. Paper presented at the 14th Annual Conference of the Society for Industrial and Organizational Psychology, April 1999, Atlanta, GA.

Smither, J. W., Reilly, R. R., Millsap, R. E., \& Pearlman, K. (1993). Applicant reactions to selection procedures. Personnel Psychology, 46(1), 49-76.

Spearman, C. (1927). The abilities of man. New York: Macmillan.

Sternberg, R. J. (1985). Beyond IQ: A triarchic theory of human intelligence. Cambridge, NY: Cambridge University Press.

Sternberg, R. J. \& Detterman, D. K. (Eds.). (1986). What is intelligence? Norwood, NJ: Ablex.

Tett, R. P., Jackson, D. N., Rothstein, M., \& Reddon, J. R. (1994). Meta-analysis of personality-job performance relations: A reply to Ones, Mount, Barrick, and Hunter (1994). Personnel Psychology, +7, 157-170.

Thorndike, R. L. (1986). The role of general ability in prediction. Journal of Vocational Behavior, 29, 332-339.

Tyler, L. E. (1986). Back to Spearman? Journal of Vocational Behavior, 29, 445-450. 
*Van Scotter, J. R. \& Motowidlo, S. J. (1996). Evidence for two factors of contextual performance: Job dedication and interpersonal facilitation. Journal of Applied Psychology, 81, 525-531.

Viswesvaran, C., Ones, D. S., \& Schmidt, F. L. (1996). Comparative analysis of the reliability of job performance ratings. Journal of Applied Psychology, 81(5), 557574.

Wiggins, J. S. (1973). Personality and prediction: Principles of personality assessment. Reading, MA: Addison-Wesley.

*Williams, M. (1999). When is personality a predictor of performance? The moderating role of autonomy. Unpublished doctoral dissertation, Florida International University.

---.. (1996). Customer service-oriented behavior: Person and situational antecedents. Unpublished master's thesis, Florida International University.

$*=$ Articles used in meta-analysis. 
Appendix A-List of Definitions for Contextual Performance 
Organ (1988)

Borman \& Motowidlo (1993)

Motowidlo \& Van Scotter (1994)

Borman \& Motowidlo (1997)

Goodman (1999)
Defined Organizational Citizenship

Behavior as similar to contextual performance or the performance on activities that are not required to succeed on the job but can affect on rating of performance as well as one's standing in an organization. Contained factors of organizational commitment but no mention of prosocial behavior outside the workplace.

Aspects of job performance which comprise all that which goes "above and beyond" what is prescribed by one's job description.

Same as above; Different in that they claim that contextual performance is not similar for all jobs.

Supplemented previous definition by claiming that contextual performance could be considered as an overarching construct which included OCBs and prosocial behavior

Contextual performance is that which does not comprise the required tasks of job performance but entails features such as interpersonal facilitation, commitment, and counterproductive behaviors. 
Appendix B-The Structural Equations Modeling Analyses 


\section{APPENDIX B}

I proposed and tested causal links between six traditionally used predictors [cognitive ability (g), agreeableness (Agr), conscientiousness (Cons), emotional stability (ES), extraversion (EX), and openness to experience (OE)] and two widely used dimensions of job performance [task performance (TP) and contextual performance (CP)]. I used partial correlations and zero-order correlations to test alternate mediational models. Variance reduction ratios were computed to index the magnitude of mediation.

Arguments could made that a more elegant approach would be to use structural equations modeling to model and test the relationships among the eight latent constructs (g, Agr, Cons, ES, EX, OE, TP, and CP). Although path analysis (i.e., LISREL, EQS) may provide a more elegant test of these models, to conduct path analysis one needs the intercorrelation among the six predictors. This entails the meta-analysis of a very vast area (of potentially thousands of articles) something far beyond the scope of a Master's thesis. Thus, the analyses was restricted to zero-order correlations, partial correlations, and variance reduction factors. Note however, the analyses of zero-order correlations and partial correlations do address the questions raised in this thesis.

However, in order to conduct a structural equation modeling, I obtained the intercorrelations among the Big Five factors of personality from the test manual for the California Psychological Inventory (Gough \& Bradley, 1997). The scales of the CPI were first grouped into the Big Five and a linear composite of scales was formed for each of the Big Five factors. For example, if scales 1, 3, 6, and 8 of the CPI were judged to assess Extraversion, a unit-weighted linear composite of the four scales was used to 
define the Big Five factor of Extraversion. I obtained the correlations between cognitive ability and Big Five personality factors from Ackerman and Heggestead (1998). These correlations were used to conduct structural equation modeling.

The subsequent analyses refer to the hypotheses, which are associated primarily with models three and four. For model three, it was hypothesized that the relationships between each of the six predictor variables and task performance would be partially mediated by contextual performance. In order to test these two hypotheses (H3a and H3b), EQS, a statistical package used for structural equation modeling, was employed. The correlations between the Big Five factors and cognitive ability are summarized in Table 9, whereas the correlations among the Big Five factors are presented in Table 10. The correlation matrix fed into the EQS program is summarized in Table $11 \& 12$. Table 11 provides observed correlations, whereas Table 12 provides the reliability corrected correlations.

Table 9

Relation ships between Big 5 and Cognitive Ability

\begin{tabular}{lccc}
\hline Variable & $\underline{N}$ & $\underline{k}$ & $\underline{r}$ \\
\hline Conscientiousness & 4850 & 3 & 02 \\
Openness to Experience & 555 & 3 & $33^{*}$ \\
Agreeableness & 941 & 6 & 01 \\
Emotional Stability & 15931 & 35 & $08^{*}$ \\
Extraversion & 6169 & 30 & $-15^{*}$ \\
\hline
\end{tabular}

Note. Table provided from Ackerm an \& Heggestad (1997) 
Table 10

Intercorrel ations between Big Five personality factors as reported in the CPI manual (Gough \& Bradley. 1996)

\begin{tabular}{llllll}
\hline Variables & 1 & 2 & 3 & 4 & 5 \\
\hline $\begin{array}{l}\text { Agreeableness } \\
\text { Conscientiousness }\end{array}$ & 57 & & & & \\
Emotional & 47 & 65 & & \\
Stability & & & & \\
Extroversion & 60 & 54 & 74 & \\
Openness to & 69 & 55 & 58 & 61 \\
Experience & & & & & \\
\hline
\end{tabular}

Table 11

An $8 \times 8$ correlation matrix using all eight $\nabla$ ariables and only observed average correlations

\begin{tabular}{lcccccccc}
\hline Variables & 1 & 2 & 3 & 4 & 5 & 6 & 7 & 8 \\
\hline Task Performance & & & & & & & \\
Contextual & $.63(33)$ & & & & & & \\
Performance & & & & & & & \\
Cognitive Ability & .24 & .04 & & & & & \\
Agreeableness & .05 & .10 & 01 & & & & \\
Conscientiousness & .11 & .08 & .02 & 57 & & & \\
Emotional Stability & 09 & .10 & .08 & 47 & 65 & & & \\
Extraversion & -02 & .02 & -.15 & 60 & 54 & .74 & & \\
Openness to & .09 & .09 & .33 & 69 & 55 & 58 & 61 & \\
Experience & & & & & & & & \\
\hline
\end{tabular}

Note. The relationship between task perform ance and contextual performance reported in parentheses is using only inter-rater correlations.

Table 12

An $8 \times 8$ correlation matrix using all eight variables and only the score correlations

\begin{tabular}{lcccccccc}
\hline Variables & 1 & 2 & 3 & 4 & 5 & 6 & 7 & 8 \\
\hline Task Performance & & & & & & & \\
Contextual & $80(52)$ & & & & & & \\
Performance & & & & & & & \\
Cognitive Ability & 32 & 05 & & & & & \\
Agreeableness & 08 & 12 & 01 & & & & \\
Conscientiousness & 14 & 10 & 02 & 57 & & & \\
Emotional Stability & 12 & 13 & 08 & 47 & 65 & & \\
Extraversion & -03 & 03 & -15 & 60 & 54 & .74 & \\
Openness to & 12 & 11 & 33 & 69 & 55 & 58 & 61 \\
Expenience & & & & & & & & \\
\hline
\end{tabular}

Note The relationship between task perform ance and contextual performance reported in parentheses is using only inter-rater correlations. 
All four models were test with (1) observed and (2) reliability corrected correlations. Both for observed as well as for reliability corrected correlations, separate analyses were conducted for inter-rater, intra-rater, and total (combining inter- and intrarater) correlations. I calculated goodness of fit indices for each of the models.

Unfortunately, however, the results were somewhat skewed by the fact the models contained strictly measured variables and correlation matrices were used as data sets. In other words, despite the fact that using the EQS approach might be more elegant, it did not prove fruitful because of the nature of the models and the variables used in each. The fit indices are summarized in Table 13. 
Table 13

Goodness of fit indices for Models 14 using Rhos and rbars

\begin{tabular}{|c|c|c|c|}
\hline Model \# & GEI & $\triangle G E I$ & RMSR \\
\hline \multicolumn{4}{|c|}{ Rho's } \\
\hline \multicolumn{4}{|l|}{ Total } \\
\hline Model 1 & 502 & .185 & 336 \\
\hline Model 2 & .514 & -092 & 332 \\
\hline Model 3 & .535 & -117 & .325 \\
\hline Model 4 & 535 & -117 & .325 \\
\hline Interrater & .500 & 181 & 337 \\
\hline Model 1 & 513 & .095 & 333 \\
\hline Model 2 & .537 & -112 & .325 \\
\hline Model 3 & .537 & -112 & 325 \\
\hline \multicolumn{4}{|l|}{ Model 4} \\
\hline \multicolumn{4}{|l|}{ Intrarater } \\
\hline Model 1 & 478 & 146 & 352 \\
\hline Model 2 & .505 & -115 & .344 \\
\hline Model 3 & 557 & -.064 & 325 \\
\hline Model 4 & 557 & -.064 & 325 \\
\hline \multicolumn{4}{|c|}{ R-bars } \\
\hline \multicolumn{4}{|l|}{ Total } \\
\hline Model 1 & 508 & 194 & 332 \\
\hline Model 2 & 517 & -086 & 329 \\
\hline Model 3 & 530 & -129 & .325 \\
\hline Model 4 & 530 & -129 & .325 \\
\hline \multicolumn{4}{|l|}{ Interrater } \\
\hline Model 1 & 510 & 198 & 331 \\
\hline Model 2 & .518 & -083 & 328 \\
\hline Model 3 & .527 & -134 & .325 \\
\hline Model 4 & .527 & -134 & 325 \\
\hline \multicolumn{4}{|l|}{ Intrarater } \\
\hline Model 1 & 492 & 169 & 342 \\
\hline Model 2 & .510 & -103 & 337 \\
\hline Model 3 & 544 & -095 & 325 \\
\hline Model 4 & .544 & -095 & 325 \\
\hline
\end{tabular}

Note. GFI=Goodness of Fit Index (LISREL-7), A GFI=A djusted Good (LISREL-7), RMSR=Root Mean Square Residual (LISREL-7)

The results of the path modeling yield evidence for one conclusion. The models of task and contextual performance must all be refined both at the predictor and criterion levels. Upon examination of Table 12 , it becomes quite apparent that none of the models fit the data set properly. The fact that the goodness-of-fit indices range from .480 to .566 is evidence of the lack of fit. In other words, none of the models (1-4) offer a tenable 
representation of relationships between the predictors and task and contextual performance. In essence, the only model that fits the relationships described in this study is model two, the null model. Of all the models, this model consistently had the highest goodness-of-fit index that suggests that none of the models that link the predictors to one of the criterion variables and, not the other, are viable. Nonetheless, the results of the structural equations modeling though elegant were not necessarily conclusive because of the limitations of the data set. Further, it is quite possible that these results were yielded because of the unusually high relationship between the criterion variables. The fact that these two variables are related at .75 in some cases leads to the realization separating the criteria may not be optimal. This clearly suggests that theories of multi-dimensional job performance still need some refinement. 